\title{
Preliminary data on fish hosts and their conservation importance for the critically endangered Pseudunio marocanus (Pallary, 1918)
}

\author{
Hassan Benaissa $^{1}$ (6) | Mohamed Ghamizi $^{1}$ | Amílcar Teixeira ${ }^{2}$ | Ronaldo Sousa ${ }^{3}$ | \\ Hanane Rassam ${ }^{1}$ | Simone Varandas ${ }^{4}$ | Manuel Lopes-Lima ${ }^{5,6}$
}

${ }^{1}$ Department of Biology, Natural History Museum of Marrakech, University of Cadi Ayyad, Marrakech, Morocco

${ }^{2}$ Centro de Investigação de Montanha (CIMO), Instituto Politécnico de Bragança, Bragança, Portugal

${ }^{3}$ Centre of Molecular and Environmental Biology (CBMA), Department of Biology, University of Minho, Braga, Portugal

${ }^{4}$ Centre for Research and Technology of Agro-Environment and Biological Sciences (CITAB-UTAD), University of Trás-os-Montes and Alto Douro, Vila Real, Portugal

${ }^{5}$ Research Centre in Biodiversity and Genetic Resources (CIBIO/InBIO), Universidade do Porto, Vairão, Portugal

${ }^{6}$ Interdisciplinary Centre of Marine and Environmental Research (CIIMAR/CIMAR), University of Porto, Matosinhos, Portugal

\section{Correspondence}

Hassan Benaissa, Department of Biology, Natural History Museum of Marrakech, University of Cadi Ayyad, B.P. 2390,

Marrakech, Morocco.

Email: benaissahassan2@gmail.com

Funding information

IUCN SOS Save our Species fund, Grant/ Award Number: 2015B-015; Mohamed bin Zayed Species Conservation Fund, Grant/ Award Number: 15256799

\section{Abstract}

1. Pseudunio marocanus (Pallary, 1918) is an endemic species of Morocco and is considered one of the world's 100 most threatened species. The life cycle of this critically endangered freshwater mussel remains unknown. However, knowledge about the discharge period of its larvae and its ecological fish hosts is crucial to adopt more effective conservation strategies.

2. Given this information gap, monitoring the presence of $P$. marocanus glochidia in fish from the Laabid River was carried out from January to May 2019 to determine the larvae discharge period. Two different approaches were used to assess the fish hosts of $P$. marocanus: (i) the determination of glochidia infestation rates of fishes in situ through monthly (from January to May) sampling in the Laabid River (Oum Er Rbia basin); and (ii) artificial infestation in laboratory trials using four fish species.

3. A peak in glochidia discharge was observed at the end of February. Fully metamorphosed juveniles were detected in all native fish species, i.e. Luciobarbus ksibi (Boulenger, 1905), Carasobarbus fritschii (Günther, 1874), Luciobarbus zayanensis Doadrio, Casal-lopez \& Yahyaoui, 2016, and Pterocapoeta maroccana Günther, 1874.

4. For the first time, the glochidia discharge period and the fish hosts of P. marocanus were determined, and this information is vital to implement future conservation measures (i.e. propagation, reinforcement of populations, possible reintroductions of $P$. marocanus, careful management of river flow by upstream dams, and the prohibition of fishing activities during the critical glochidia discharge period).

5. Given the increasing human pressure on freshwater habitats and biodiversity in Morocco, it is essential to preserve the native ichthyofauna to conserve this rare pearl mussel species.

KEYWORDS

freshwater mussels, glochidia, infestation, Laabid River, Pseudunio marocanus, unionids 


\section{1 | INTRODUCTION}

Invertebrate groups such as freshwater mussels (order Unionida) have received more attention in recent years given the extensive decline of their populations worldwide (Strayer et al., 2004; Lopes-Lima et al., 2014; Lopes-Lima et al., 2017a; Lopes-Lima et al., 2018; Zieritz et al., 2018). Freshwater mussels have a unique life cycle in which the larvae (glochidia) must complete a temporary, but obligatory, stage of being attached to a vertebrate host, usually a fish species (for a review see Modesto et al., 2018), before metamorphosing into freeliving juveniles (Arey, 1921; Coker et al., 1921; Reis, Collares-Pereira \& Araujo, 2014). Therefore, the identification of potential hosts is crucial for their conservation (Ferreira-Rodríguez et al., 2019). Information on the hosts is also useful in understanding the evolutionary relationships among the main groups of freshwater mussels (Lopes-Lima et al., 2017b).

Within the most threatened family of freshwater bivalves (i.e. the Margaritiferidae) the genus Margaritifera was recently split into four genera, based on morphological and molecular characters but also on distinct ecological traits, such as the fish host groups used (Lopes-Lima et al., 2018). For example, whereas species from the genus Margaritifera use salmonid or the closely related esocid fishes (Young \& Williams, 1984; Taeubert et al., 2010; Österling \& Larsen, 2013; Murzina, leshko \& Zotin, 2017; Garrison, Johnson \& Whelan, 2021), within Pseudunio, until now, hosts were only known for the European Pseudunio auricularius and include sturgeons, lampreys, and a blenny (Altaba, 1990; Araujo \& Ramos, 1998; Araujo, Bragado \& Ramos, 2000; Altaba \& López, 2001; Araujo, Bragado \& Ramos, 2001; Araujo, Cámara \& Ramos, 2002; López \& Altaba, 2005; López et al., 2007; Soler et al., 2018; Soler et al., 2019). For this purpose, the knowledge of the fish hosts of Pseudunio marocanus (Pallary, 1918) is a crucial step that will support (or not) the genetic analyses used to evaluate its evolutionary relationships within the family.

Pseudunio marocanus is an endemic species of Morocco listed as Critically Endangered B1ab(i,ii,iii,iv), B2ab(i,ii,iii,iv) (Van Damme \& Ghamizi, 2010; Gomes-dos-Santos et al., 2019) and considered among the 100 most threatened species in the world (Baillie \& Butcher, 2012). The species has been declining significantly, mainly in the southern part of the country where many populations have been extirpated by the conversion of perennial rivers into non-perennial or intermittent rivers in response to climate change, the intensification of land use, water abstraction, and river impoundments, and through pollution caused by increasing agricultural, industrial, and domestic activities (Sousa et al., 2016; Sousa et al., 2018; Gomes-dos-Santos et al., 2019; Sousa et al., 2019). This species is characterized by its large size (Araujo et al., 2009; Sousa et al., 2018), and its principal habitats are shallow areas with lotic conditions in middle-sized rivers. Mussels are mainly located near the banks and in coarse sediments, consisting predominantly of cobbles and boulders, associated with bankside vegetation (Araujo et al., 2009; Van Damme \& Ghamizi, 2010). Its distribution is currently limited to the lower sections of the Laabid River in the Oum Er Rabia basin, and the
Bouhlou River and associated irrigation canals in the Sebou basin (Sousa et al., 2016; Sousa et al., 2018; Sousa et al., 2019). During recent surveys, old shells were also found in the lower section of the Moulouya basin, but no live specimens were retrieved (authors' pers. observ.). Therefore, it is important to conduct more detailed surveys in different basins, as the discovery of new populations is essential for the long-term survival of the species as well as for the future implementation of conservation measures.

Being highly threatened and considered as the only margaritiferid representative species in Africa, the systematics, distribution, and conservation status of this species have been widely revised over the last decades (Mandahl-Barth, 1988; Daget, 1998; Araujo et al., 2009; Lopes-Lima et al., 2017a, Lopes-Lima et al., 2018). Nevertheless, most of its life-history traits (e.g. reproductive cycle, glochidia discharge, age of maturity, fertility, and fish hosts) and basic population features (e.g. abundance trends, size structure, and demography) are still poorly or completely unknown. This hinders the potential conservation measures (but see Sousa et al., 2016; Sousa et al., 2018; Sousa et al., 2019) needed to maintain the long-term survival of the populations, as implemented for other European freshwater mussel species, for example (MARM, 2009; Geist, 2010; Prié, Philippe \& Cochet, 2011; Taeubert, Gum \& Geist, 2012; Lopes-Lima et al., 2017c; Ferreira-Rodríguez et al., 2019; Stoeckl, Denic \& Geist, 2020). Indeed, this lack of basic autecological information may impair the assessment of conservation status, the selection of priority conservation and rehabilitation areas, and guidance for the establishment of propagation or reintroduction programmes (Lopes-Lima et al., 2020, Lopes-Lima et al., 2021).

Given the conservation importance of $P$. marocanus and the urgency to collect information on its basic biological features, this work aimed to: (i) identify the glochidia discharge period; (ii) assess the infestation rates of $P$. marocanus under natural conditions; and (iii) assess the ability of the $P$. marocanus fish hosts to transform glochidia into juveniles successfully, using fish infestations in the laboratory.

\section{2 | MATERIAL AND METHODS}

\subsection{Study area}

The study was conducted in the Laabid River, Morocco (Figure 1), a river with an approximate length of $200 \mathrm{~km}$ that originates in the Atlas Mountains and drains to the Oum Er Rbia River. The Laabid basin is located between the High Atlas and the plain of Tadla and is considered one of the most important basins in terms of water resources of Morocco, being used for irrigation and hydropower generation. The annual average rainfall in Laabid River between 2018 and 2019 was 203 mm (Agence du bassin hydraulique de l'Oum Er Rabia, 2019).

The population of $P$. marocanus is limited upstream by the Bin El Ouidane dam and is distributed discontinuously in the middle and lower stretches of the river (Sousa et al., 2016). The study area is 
FIGURE 1 Map of the study area and the location of the sampling site

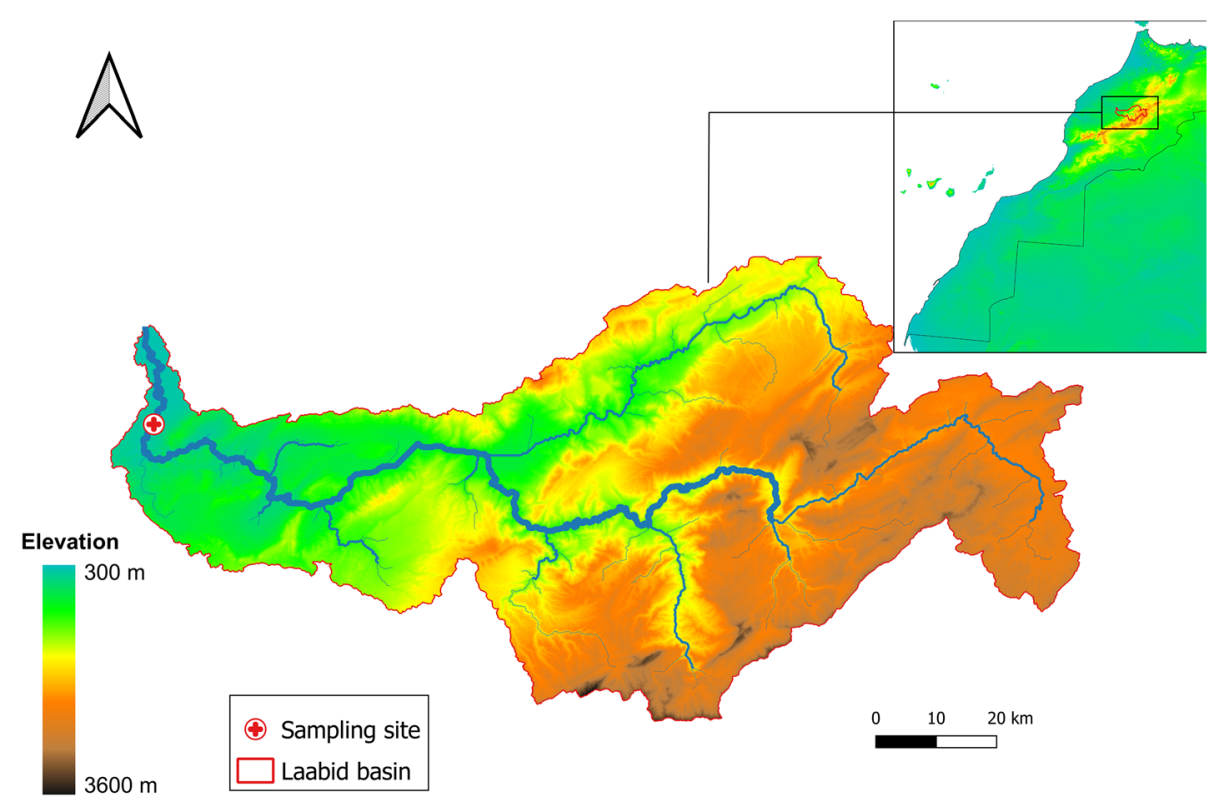

characterized by a permanent flow and a substrate consisting of cobbles, gravel, sands, and occasional mud. The riparian vegetation is represented by species such as Juncus acutus, Nerium oleander, Populus alba, Tamarix gallica, Vitex agnus castus, Ricinus communis, and Phragmites australis.

\section{2 | Field sampling}

The density of $P$. marocanus was determined in the study area by counting visible individuals (excavation of the sediments was not performed to avoid disturbance of this Critically Endangered species) within $1-\mathrm{m}^{2}$ quadrats (with 50 quadrats distributed randomly over an area of $200 \mathrm{~m}^{2}$ ) adjacent to both river banks. All P. marocanus collected were measured to determine their shell length (using calipers with an accuracy of $0.1 \mathrm{~mm}$ ), and then carefully returned to the river in their original position. To infer the population structure and to confirm the existence of recent recruitment, a size-frequency distribution with 5-mm intervals was used. Pseudunio marocanus juveniles were categorized using the biologically based definition (up to $100 \mathrm{~mm}$ ) used by Araujo \& Ramos (2000) in Iberia for the sister taxon P. auricularius.

As its closest relative, $P$. auricularius, discharges glochidia in late February, monitoring for the presence of $P$. marocanus glochidia in fish from the Laabid River was carried out from January to May 2019. It should be noted that in the study area Potomida littoralis lives in sympatry with $P$. marocanus. Potomida littoralis individuals were also checked for gravidity and potential glochidia release, but no gravid mussels or larvae release events were detected during the study period. This species is also being monitored for glochidia release, which only occurs in late spring in this river (authors' pers. observ.).

For characterizing the fish community, an area of $100 \mathrm{~m}^{2}$ was surveyed for $20 \mathrm{~min}$ (covering all habitats, e.g. riffles, pools, banks, and the centre of the river channel) using electrofishing (ELT II, 300/300 V, DC; Hans Grassl GmbH, Schönau am Königssee, Germany). Fish species were identified and the density and relative abundance were also determined.

For glochidia infestation, all fish gills were visually inspected on site (with a magnification app on a mobile phone, $10 \times$ ) by raising the fish operculum. Infested fish (139 fish individuals inspected) were brought to the laboratory in a tank for the confirmation and the evaluation of glochidial load. All encysted glochidia were counted (using a CH 9435 loupe; Leica Microsystems, Wetzlar, Germany) for each fish to estimate the number of glochidia per individual of a given species per month. Encysted glochidia were then pipetted and placed in tubes containing 95\% ethanol. Each tube was tagged with the site identification, fish taxonomy, and date, and then deposited at the Natural History Museum of Marrakech. To determine whether there were any significant differences between the proportions of fish found in the Laabid River and those infested, a chi-square test was carried out using MINITAB 14.

\section{3 | Experimental infestation}

For the laboratory experiments, gravid $P$. marocanus females (verified in the field by carefully opening the shells and observing the swelling of the gills) were collected by snorkelling (limited to eight individuals, owing to the imperilled status of the species) and transported to the laboratory in a refrigerated tank. The target fish species for the infestation experiments were selected based on their coexistence with P. marocanus (see Results and Figure 2). The individual fishes were captured by electrofishing (in another upstream site, where mussels are not present), as described above, and transported alive (96 individuals) to the laboratory in a tank $\left(22{ }^{\circ} \mathrm{C}\right)$ with river water. Smaller fish were chosen to reduce any 

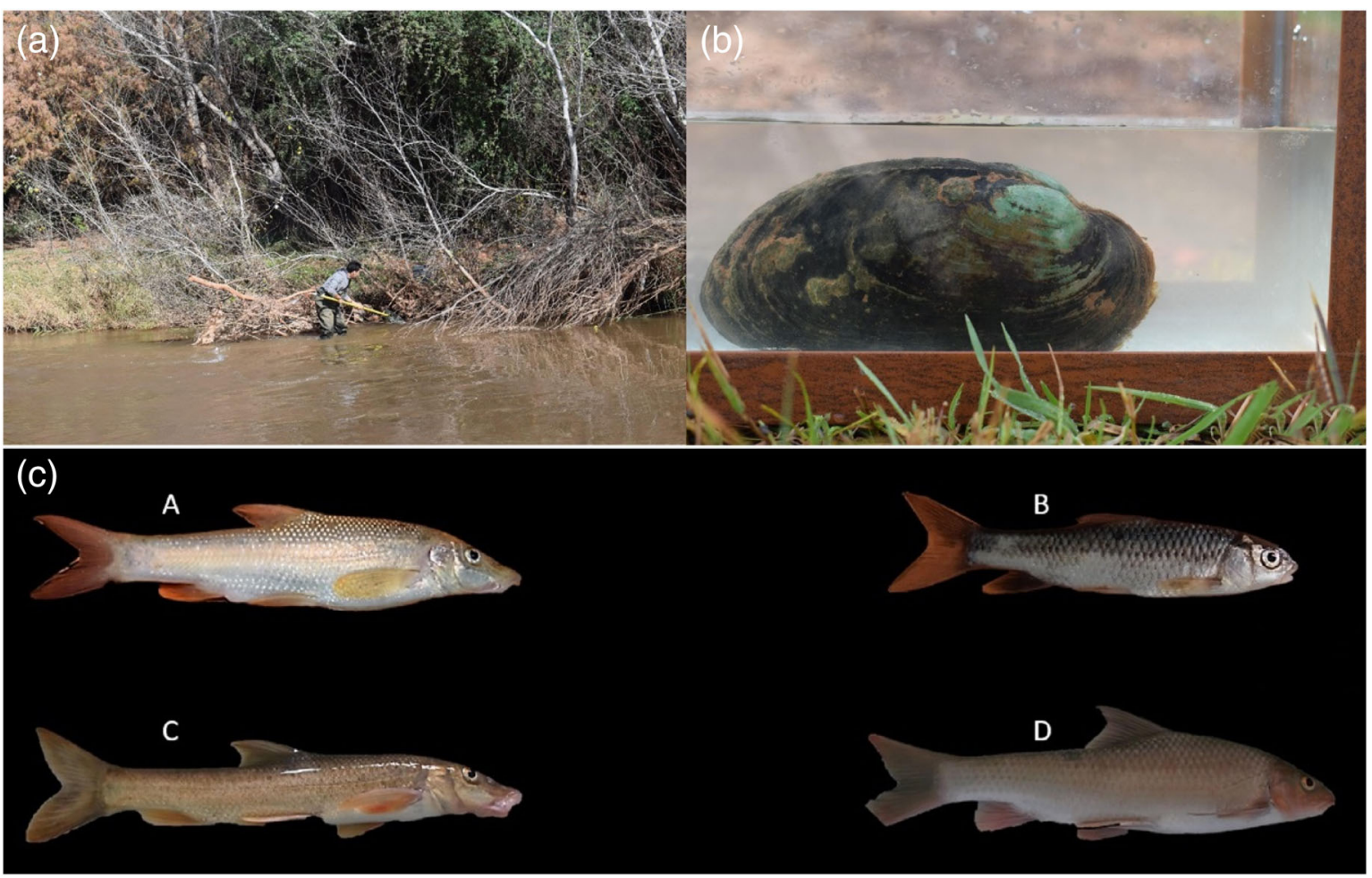

FIGURE 2 (a) Electrofishing operation. (b) Adult Pseudunio marocanus (Pallary, 1918). (c) A, Luciobarbus ksibi (Boulenger, 1905); B, Carasobarbus fritschii (Günther, 1874); C, Luciobarbus zayanensis Doadrio, Casal-Lopez \& Yahyaoui, 2016; D, Pterocapoeta maroccana Günther, 1874

potential biases from acquired immunity by previous exposure to glochidia.

To determine the transformation of $P$. marocanus glochidia into juveniles, artificial infestations were performed in the laboratory. For this, the gravid mussels and different fish species collected in the Laabid River were maintained at the Museum of Natural History of Marrakech in aerated aquaria, with the temperature held at $24-25{ }^{\circ} \mathrm{C}$. Water exchange and inspection for released glochidia were carried out daily (following the procedure described in Taeubert, Gum \& Geist, 2012).

The laboratory experiments on fish infestation were conducted from 19 February to 28 May 2019. Glochidia were extracted from the gills of gravid mussels $(n=8)$ through the exhalant apertures with a pipette (around 800 glochidia per litre). Glochidia and individual fishes ( $n=96$ ) from all the species collected (Carasobarbus fritschii, Luciobarbus ksibi, Luciobarbus zayenensis and Pterocapoeta maroccana) were mixed for $10 \mathrm{~min}$ in a tray $(10 \mathrm{~L})$ to ensure identical conditions for glochidia uptake. Each fish species was placed in a separate aquarium with a net at the bottom to avoid glochidia consumption by the fish (six individuals of each species, with four replicate aquaria per species). The water in the aquaria was siphoned daily through a sieve of $60 \mu \mathrm{m}$ to check for glochidia or juveniles. The metamorphosis of the glochidia into juveniles was evaluated under a stereoscope by observing any active foot movement. It should be noted that the number of juveniles released compared with the size and weight of the fish hosts was not examined in this study. After counting, the transformation rate (tr) for each fish species was calculated by dividing the number of juveniles by the attached and dead glochidia in the water (tr = number of juveniles/ number of juveniles + number of dead glochidia $* 100$ ). The number of degree-days was calculated by the sum of the daily temperatures during days of transformation success.

The handling of all animals and procedures in the laboratory and in the field were ethically reviewed and approved by the Morrocan High Commission for Water and Forests (HCEFLCD, ref. 4410).

\section{$3 \mid$ RESULTS}

\section{1 | Mussel size structure and fish species composition}

The mean $( \pm S D)$ density of $P$. marocanus in the study site was $12.3 \pm 2.6$ ind. $\mathrm{m}^{-2}$, with a dominance of older individuals (mean \pm SD length of $110.52 \pm 17.80 \mathrm{~mm}$ ) (Figure 3). Most mussels were found in low-flow areas near the river bank. In total, 139 fish individuals (all within the family (yprinidae) belonging to four species (i.e. P. maroccana, L. ksibi, L. zayanensis, and C. fritschii) were collected between January and May 2019 in the Laabid River. The total mean fish density was 0.28 ind. $\mathrm{m}^{-2}$. The lowest density of fish was at the beginning of February $\left(0.20\right.$ ind. $\left.\mathrm{m}^{-2}\right)$ and the highest was in May (0.37 ind. $\mathrm{m}^{-2}$ ) (Table 1). During the 5 months of monitoring, C. fritschii was the most abundant (43.0\%), followed by L. zayanensis (25.0\%), L. ksibi (17.7\%), and P. maroccana (14.3\%) (Table 1). 
FIGURE 3 Size-frequency distribution of Pseudunio marocanus in the sampling site $(n=196)$

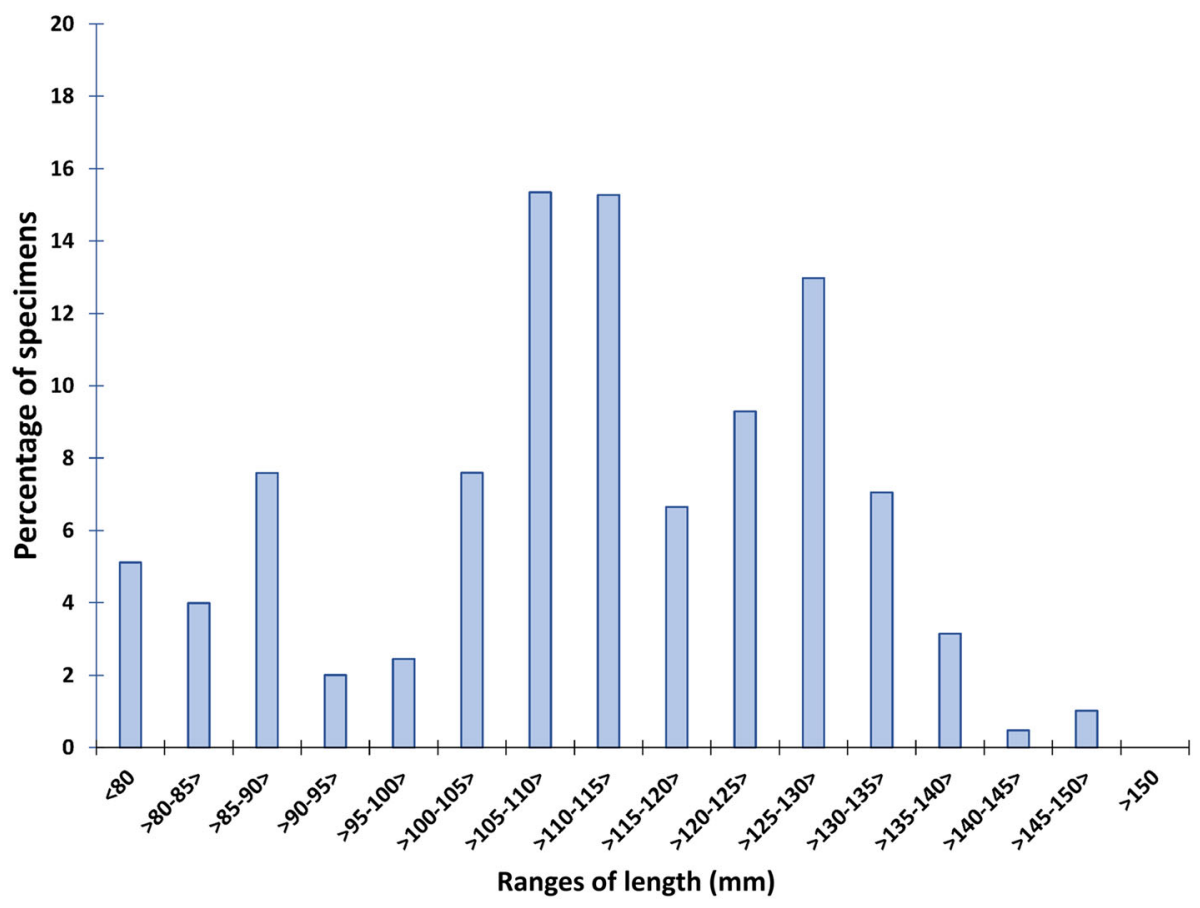

TAB LE 1 Fish species composition, relative abundance, and fish density (ind. $\mathrm{m}^{-2}$ ) in the Laabid River

\begin{tabular}{|c|c|c|c|c|c|c|c|c|c|c|c|c|c|c|}
\hline & \multicolumn{2}{|c|}{7 January } & \multicolumn{2}{|c|}{23 January } & \multicolumn{2}{|c|}{9 February } & \multicolumn{2}{|c|}{26 February } & \multicolumn{2}{|c|}{16 March } & \multicolumn{2}{|c|}{14 April } & \multicolumn{2}{|c|}{10 May } \\
\hline Carasobarbus fritschii & 0.14 & 52.63 & 0.10 & 41.18 & 0.10 & 35.71 & 0.17 & 54.55 & 0.14 & 50 & 0.09 & 28.57 & 0.19 & 38.46 \\
\hline Pterocapoeta maroccana & 0.03 & 10.53 & 0.03 & 11.76 & 0.01 & 7.14 & 0.04 & 13.64 & 0.04 & 15 & 0.06 & 19.05 & 0.04 & 23.08 \\
\hline Luciobarbus zayanensis & 0.06 & 21.05 & 0.07 & 29.41 & 0.01 & 21.43 & 0.07 & 22.73 & 0.06 & 20 & 0.10 & 33.33 & 0.10 & 26.92 \\
\hline Luciobarbus ksibi & 0.04 & 15.79 & 0.04 & 17.65 & 0.07 & 35.71 & 0.03 & 9.09 & 0.04 & 15 & 0.06 & 19.05 & 0.04 & 11.54 \\
\hline
\end{tabular}

Abbreviations: A\%, relative abundance (\%); D, density.

\subsection{Natural infestation of fish}

In total, 68 glochidia on 139 fish inspected were observed from January to May 2019. The mean number of glochidia per individual did not greatly differ between species during the release period of the glochidia (from mid-February to May). Carasobarbus fritschii and P. maroccana were the species most infested $(0.97$ and 0.88 glochidia per individual fish, respectively); the remaining species were less infested (with 0.57 and 0.33 glochidia per individual fish for L. zayanensis and L. ksibi, respectively). The peak of glochidial infestation was observed at the end of February (Figure 4). Significant differences were found between the proportion of fish sampled and the proportion of fish that were infested $\left(\chi^{2}=17.65, p<0.05\right)$.

\section{3 | Experimental infestation}

The release of mature glochidia (total length 130-140 $\mu \mathrm{m}$ ) began on 9 March 2019. The glochidia are D-shaped and no hooks were observed on the margins of the valves (Figure 5). The transformation rate (tr) and the transformation success period (tsp) of $P$. marocanus juveniles varied among different fish host species. For $C$. fritschii, fully transformed juveniles of $P$. marocanus first appeared on the 22nd day post infestation $(\mathrm{PI})$ and were then recorded until 28 days $\mathrm{PI}$ ( $t r=1.18 \%, t s p=528-700$ degree-days). For $P$. maroccana, juveniles were observed from 24 to 29 days PI ( $t r=12.24 \%$, tsp $=576-$ 724 degree-days). Juveniles of $L$. zayanensis were released from 23 to 31 days $\mathrm{PI}(\mathrm{tr}=4.36 \%$, $t s p=552-744)$; for $L$. ksibi, the juveniles were observed between 28 and 32 days PI ( $t r=2.01 \%$, tsp $=700-768$ ) (Figure 6). No fish mortality was observed before and during the experiment.

\section{4 | DISCUSSION}

The mean density of $P$. marocanus in the study area can be considered high and agrees with previous estimates for the Laabid River (Sousa et al., 2016). The low number of juveniles found and the dominance 


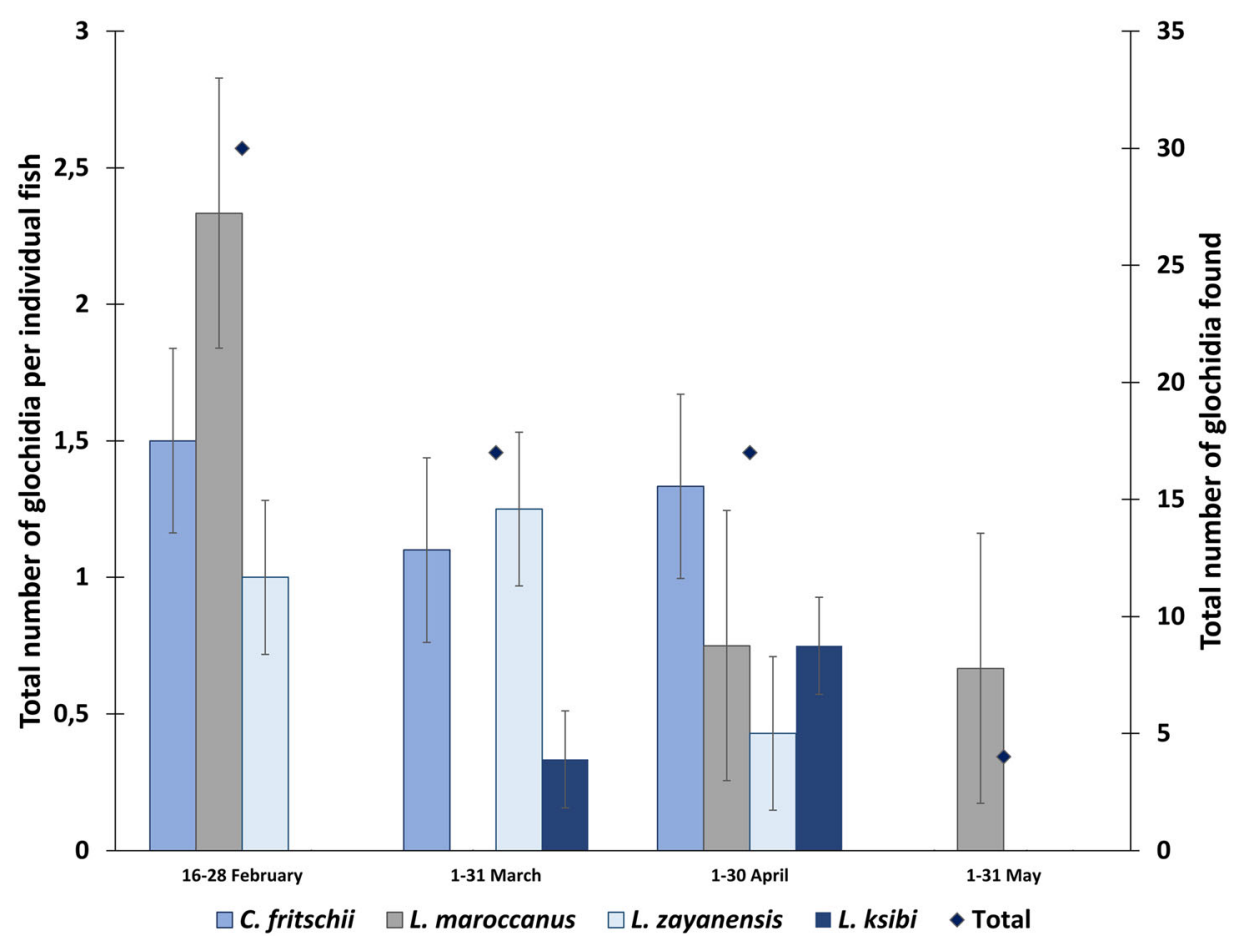

FIGURE 4 Infestation rate of glochidia per individual fish species and the total number of glochidia of Pseudunio marocanus found in the Laabid River from January to May 2019 ( $n=68$ glochidia/89 fish)

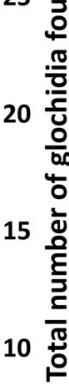

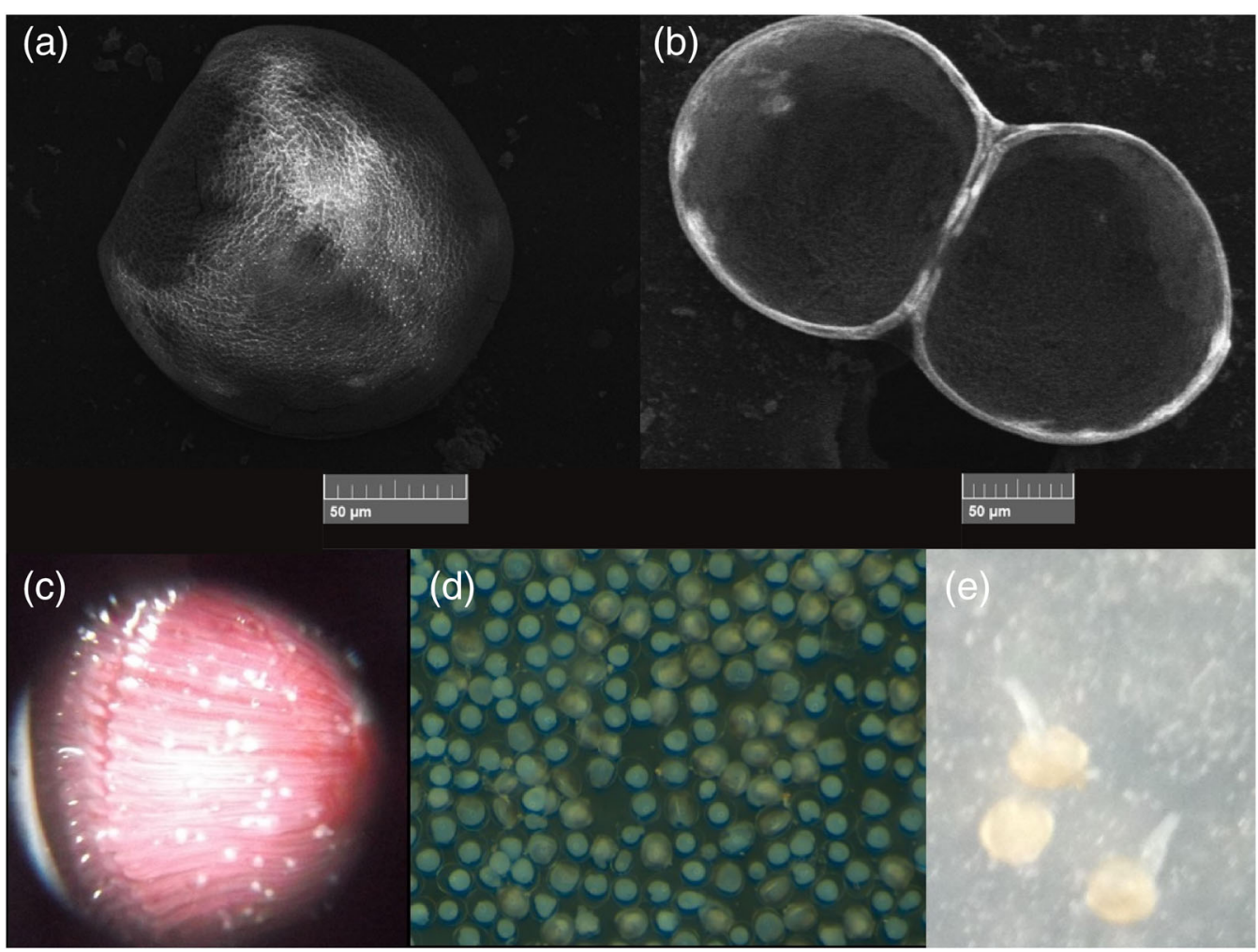

FIGURE 5 (a, b) Pseudunio marocanus glochidia. (c) Infestation of gill by glochidia. (d) Immature glochidia of $P$. marocanus. (e) Juveniles of $P$. marocanus

of older individuals can be explained by the survey method used to avoid disturbance of small mussels in addition to a possible reduction in recruitment rates in recent years.
The period of glochidia discharge of $P$. marocanus was recorded for the first time here as being between February and May, with a peak at the end of February. This period occurs earlier than the 
FIGURE 6 Cumulative excystment percentage of glochidia transformation into juveniles per individual fish species over time in degree-days

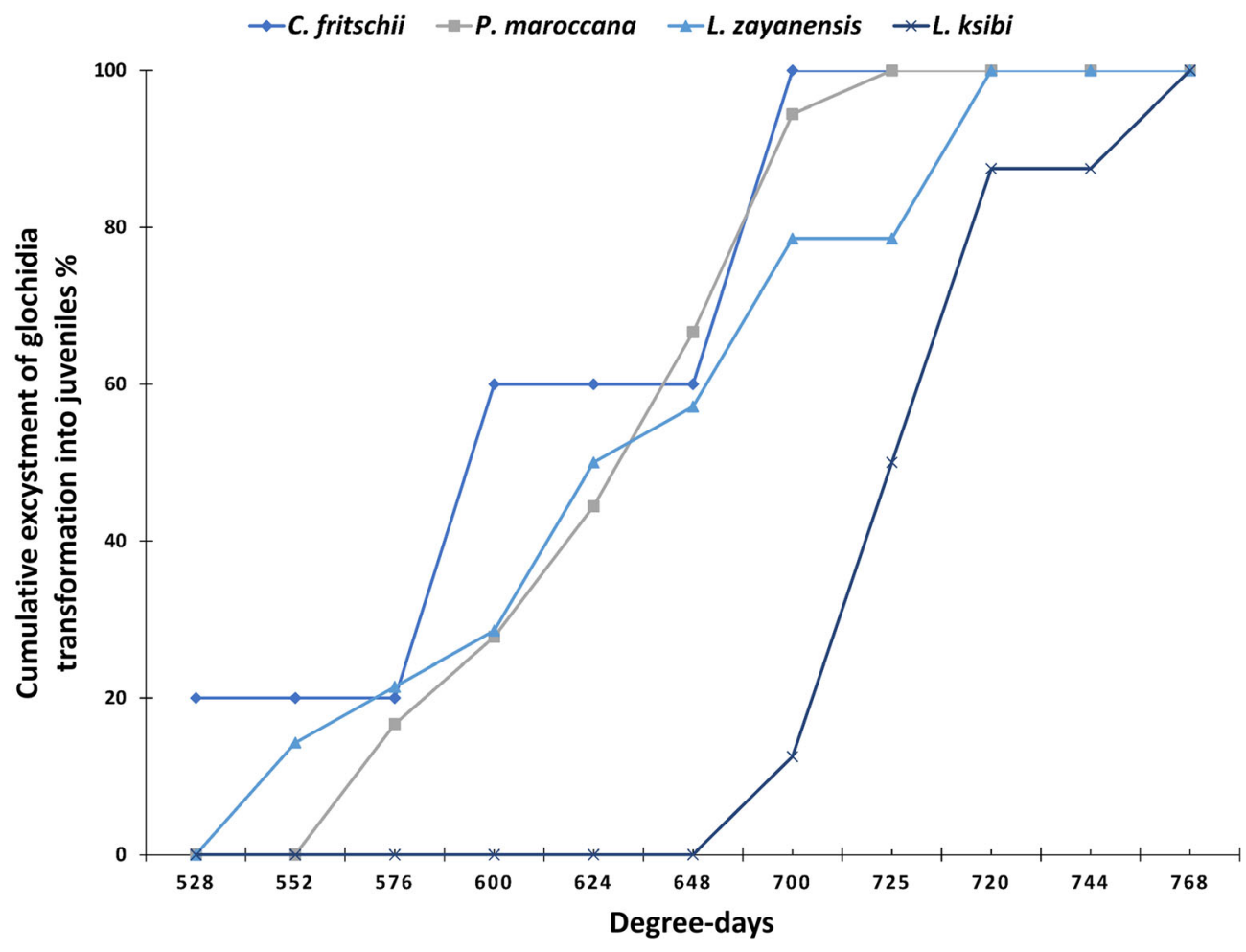

congeneric species $P$. auricularius in Spain (with peak release in March; Araujo, Bragado \& Ramos, 2000) and in France (with peak release mainly in April; Soler et al., 2018). This difference in the timing of glochidial release between both species may be related to interspecific differences or latitudinal differences in river temperatures as noted, for example, for $P$. auricularius between the populations of Spain and France (Soler et al., 2018).

Four native cyprinid fish species are reported here for the first time as suitable hosts for $P$. marocanus. The distribution of the four species is restricted to north-west Africa (Azeroual, 2003; CasalLópez et al., 2015; Doadrio et al., 2016), with three of these species endemic to Morocco. These fish species have also been reported previously as fish hosts for the Moroccan endemic and critically endangered freshwater mussel species Unio foucauldianus in the Laabid River (Benaissa et al., 2019). All the fish monitored from the Laabid site present a low infestation rate, probably because of the low density of mussels in the Laabid River, the lack of a spatial overlap between the glochidia and the fish species studied, or other environmental conditions not measured in this study. Alternatively, the lowest glochidial loads in the Laabid River may also be explained by the absence of more suitable fish host species in the study area (for example, a recent suitable host found for $P$. auricularius is Petromyzon marinus; Soler et al., 2019).

Although future studies may assess the suitability of $P$. marocanus with other fish species of the Laabid River, the four species of Cyprinidae reported in this study should be used in the conservation programmes dedicated to this bivalve. The identification of suitable fish hosts is the first step in implementing several conservation measures, such as propagation programmes, reinforcement of populations, and possible future reintroductions. The results of the laboratory infestation trials showed low transformation rates of glochidia into juveniles (<13\%) for all fish species, suggesting that the cyprinids in this study may be considered as marginal host species for $P$. marocanus. As this study is restricted to a unique sampled site, other localities in the Laabid River (or even in the Bouhlou River, Sebou basin) should be assessed to see the response of other fish species, including migratory fish species such as Anguilla anguilla and Salaria atlantica, and invasive species that occur in the Laabid River, such as Gambusia holbrooki, Oreochromis niloticus, Lepomis gibbosus and Lepomis macrochirus.

The glochidia have a similar shape to other margaritiferid larvae and are similar in size to the congeneric $P$. auricularius, but are larger than larvae of the genus Margaritifera (Araujo \& Ramos, 1998; Soler et al., 2018). The encystment period varied across the different host species and the timing varied between 528 and 768 degree-days at 24-25 ${ }^{\circ} \mathrm{C}$. This result is within the same range of values described previously for other species of the Margaritiferidae, such as P. auricularius that have a development time of 700 degree-days for a temperature of $23-24{ }^{\circ} \mathrm{C}$ (Araujo \& Ramos, 2000). Other studies have found different results, with a development time of 1,000 to 1,100 degree-days for temperatures between 16 and $18{ }^{\circ} \mathrm{C}$ for P. auricularius (Araujo, Cámara \& Ramos, 2002). These differences in development times may result from the variable degrees of maturity of the glochidia used for each of the trials or from differences in host suitability among fishes. The latter assumption is supported by findings from other species of freshwater mussels, where pronounced differences in metamorphosis success and development times have been observed with the same glochidia on different host fish species 
(Huber \& Geist, 2017; Huber \& Geist, 2019a; Huber \& Geist, 2019b). Therefore, when considering the captive rearing of $P$. marocanus it may be important not to rely only on the use of one single host species, to avoid any potential selection effect.

\section{5 | CONCLUSIONS}

To avoid the extinction of $P$. marocanus in the Laabid River, the species urgently needs to benefit from conservation action plans. Ideally, the restoration of abiotic and biotic conditions for the survival and recruitment of $P$. marocanus will be the best management action. However, this would be financially demanding and so less costly measures such as reproduction in captivity, propagation, and reintroductions would be easier to implement. In addition, the more careful management of river flow by upstream dams and a prohibition of fishing during the critical glochidia discharge period should also be enforced. The data reported here are key to implement these measures and should be complemented by outreach activities in order to engage local citizens. Alarming indicators are reported in this study, such as low natural infestation on fish hosts and a low rate of metamorphosis. This situation will be further exacerbated by global warming scenarios, which predict that many rivers in Morocco are likely to cease flow permanently and turn into temporary and irregularly flowing systems (Gomes-dosSantos et al., 2019). This has already been described for the recently extirpated $P$. marocanus population from the nearby Derna River (Sousa et al., 2016). The introduction of non-native fishes in different Moroccan rivers, including the Laabid, also represents a direct threat to $P$. marocanus and the native fish fauna, as these non-native species do not usually function as suitable hosts for freshwater mussels (Dias et al., 2020).

\section{ACKNOWLEDGEMENTS}

The authors would like to express thanks to the High Commission for Water and Forests (HCEFLCD) for granting permission to use electrofishing in the Moroccan basins. This study was conducted within the scope of the project 'Biodiversity and conservation of the critically endangered freshwater mussels in Morocco: ecogeographic, genetic and physiological information', funded by Mohamed Bin Zayed Species Conservation Fund (ref. 15256799), and the project 'Breeding the most endangered bivalve on Earth: Margaritifera marocana', funded by the International Union for Conservation of Nature (IUCN) Save Our Species fund (ref. 2015B-015).

\section{CONFLICT OF INTEREST}

All authors declare that they have no conflicts of interest associated with this work.

\section{DATA AVAILABILITY STATEMENT}

The data that support the findings of this study are available from the corresponding author upon reasonable request.

\section{ORCID}

Hassan Benaissa (D) https://orcid.org/0000-0002-0450-5220

Manuel Lopes-Lima (D) https://orcid.org/0000-0002-2761-7962

\section{REFERENCES}

Agence du bassin hydraulique de l'Oum Er Rabia (ABHOER). (2019). Rapport sur la situation hydrologique du bassin d'Oum Er Rabia. Maroc.

Altaba, C.R. (1990). The last known population of Margaritifera auricularia: A conservation priority. Biological Conservation, 52(4), 271-286. https://doi.org/10.1016/0006-3207(90)90072-W

Altaba, C.R. \& López, M.A. (2001). Experimental demonstration of viability for the endangered giant pearlmussel Margaritifera auricularia (Bivalvia: Unionoida) in its natural habitat. Bolletí de la Societat d'Història Natural de les Balears, 44, 15-21.

Araujo, R., Bragado, D. \& Ramos, M.A. (2000). Occurrence of glochidia of the endangered Margaritifera auricularia (Spengler, 1793) and other mussel species (Bivalvia: Unionoida) in drift and on fishes in an ancient channel of the Ebro River, Spain. Archiv für Hydrobiologie, 148(1), 147160. https://doi.org/10.1127/archiv-hydrobiol/148/2000/147

Araujo, R., Bragado, D. \& Ramos, M.A. (2001). Identification of the river blenny, Salaria fluviatilis, as a host to the glochidia of Margaritifera auricularia. Journal of Molluscan Studies, 67(1), 128-129. https://doi. org/10.1093/mollus/67.1.128

Araujo, R., Cámara, N. \& Ramos, M.A. (2002). Glochidium metamorphosis in the endangered freshwater mussel Margaritifera auricularia (Spengler, 1793): A histological and scanning electron microscopy study. Journal of Morphology, 254(3), 259-265. https://doi.org/10. 1002/jmor.10031

Araujo, R. \& Ramos, M.A. (1998). Description of the glochidium of Margaritifera auricularia (Spengler, 1793) (Bivalvia, Unionidae). Philosophical Transactions of the Royal Society of London B, 353(1375), 1553-1559. https://doi.org/10.1098/rstb.1998.0309

Araujo, R. \& Ramos, M.A. (2000). Status and conservation of the relict giant European freshwater pearl mussel Margaritifera auricularia (Spengler, 1793). Biological Conservation, 96(2), 233-239. https://doi. org/10.1016/S0006-3207(00)00075-6

Araujo, R., Toledo, C., Van Damme, D., Ghamizi, M. \& Machordom, A. (2009). Margaritifera marocana (Pallary, 1918): A valid species inhabiting Moroccan rivers. Journal of Molluscan Study, 75(2), 95-101. https://doi.org/10.1093/mollus/eyn043

Arey, L.B. (1921). An experimental study on glochidia and the factors underlying encapsulation. Journal of Experimental Zoology, 33(2), 463-499. https://doi.org/10.1002/jez.1400330209

Azeroual, A. (2003). Monographie des Poissons des eaux continentales du Maroc: systématique, distribution et écologie ( $\mathrm{PhD}$ thesis). Université Mohammed V-Agdal, Rabat, Morocco.

Baillie, J.E.M. \& Butcher, E.R. (2012). Priceless or worthless? The world's most threatened species. London: Zoological Society of London.

Benaissa, H., Teixeira, A., Lopes-Lima, M., Sousa, R., Varandas, S., Rassam, H. et al. (2019). Fish hosts of the freshwater mussel Unio foucauldianus Pallary, 1936. Aquatic Conservation: Marine and Freshwater Ecosystems, 29(12), 2176-2184. https://doi.org/10.1002/ aqc.3234

Casal-López, M., Perea, S., Yahyaoui, A. \& Doadrio, I. (2015). Taxonomic review of the genus Luciobarbus Heckel, 1843 (Actinopterygii, Cyprinidae) from Northwestern Morocco with the description of three new species. Graellsia, 71(2), e027. https://doi.org/10.3989/graellsia. 2015.v71.135

Coker, R.E., Shira, A.F., Clark, H.W. \& Howard, A.D. (1921). Natural history and propagation of fresh-water mussels. Document No. 893. Bulletin of the Bureau of Fisheries, 37, 77-181. https://doi.org/10.3989/ graellsia.2015.v71.135 
Daget, J. (1998). Catalogue raisonné des Mollusques bivalves d'eau douce Africains. Leiden \& Paris: Backhuys Publishers \& Orstom.

Dias, A.R., Teixeira, A., Lopes-Lima, M., Varandas, S. \& Sousa, R. (2020). From the lab to the river: Determination of ecological hosts of Anodonta anatina. Aquatic Conservation: Marine and Freshwater Ecosystems, 30(5), 988-999. https://doi.org/10.1002/aqc.3328

Doadrio, I., Casal-López, M., Perea, S. \& Yahyaoui, A. (2016). Taxonomy of rheophilic Luciobarbus Heckel, 1842 (Actinopterygii, Cyprinidae) from Morocco with the description of two new species. Graellsia, 72(1), e039. https://doi.org/10.3989/graellsia.2016.v72.153

Ferreira-Rodríguez, N., Akiyama, B.Y., Aksenova, O., Araujo, R., Barnhart, C., Bespalaya, Y. et al. (2019). Research priorities for freshwater mussel conservation assessment. Biological Conservation, 231, 77-87. https://doi.org/10.1016/J.BIOCON.2019.01.002

Garrison, N.L., Johnson, P.D. \& Whelan, N.V. (2021). Conservation genomics reveals low genetic diversity and multiple parentage in the threatened freshwater mussel, Margaritifera hembeli. Conservation Genetics, 22, 217-231. https://doi.org/10.1007/s10592-02001329-8

Geist, J. (2010). Strategies for the conservation of endangered freshwater pearl mussels (Margaritifera margaritifera L.): A synthesis of Conservation Genetics and Ecology. Hydrobiologia, 644, 69-88. https://doi.org/10.1007/s10750-010-0190-2

Gomes-dos-Santos, A., Froufe, E., Gonçalves, D.V., Sousa, R., Prié, V., Ghamizi, M. et al. (2019). Freshwater conservation assessments in (semi) arid regions: Testing river intermittence and buffer strategies using freshwater mussels (Bivalvia, Unionida) in Morocco. Biological Conservation, 236, 420-434. https://doi.org/10.1016/j.biocon.2019. 05.038

Huber, V. \& Geist, J. (2017). Glochidial development of the freshwater swan mussel (Anodonta cygnea, Linnaeus 1758) on native and invasive fish species. Biological Conservation, 209, 230-238. https://doi.org/10. 1016/j.biocon.2017.02.030

Huber, V. \& Geist, J. (2019a). Host fish status of native and invasive species for the freshwater mussel Anodonta anatina (Linnaeus, 1758). Biological Conservation, 230, 48-57. https://doi.org/10.1016/j.biocon. 2018.12.007

Huber, V. \& Geist, J. (2019b). Reproduction success of the invasive Sinanodonta woodiana (Lea 1834) in relation to native mussel species. Biological Invasions, 21, 3451-3465. https://doi.org/10.1007/s10530019-02060-3

Lopes-Lima, M., Burlakova, L.E., Karatayev, A.Y., Mehler, K., Seddon, M. \& Sousa, R. (2018). Conservation of freshwater bivalves at the global scale: Diversity, threats and research needs. Hydrobiologia, 810(1), 1-14. https://doi.org/10.1007/s10750-017-3486-7

Lopes-Lima, M., Fonseca, M.M., Aldridge, D.C., Bogan, A.E., Gan, H.M., Ghamizi, M. et al. (2017a). The first Margaritiferidae male (M-type) mitogenome: Mitochondrial gene order as a potential character for determining higher-order phylogeny within Unionida (Bivalvia). Journal of Molluscan Studies, 83(2), 249-252. https://doi.org/10.1093/mollus/ eyx009

Lopes-Lima, M., Froufe, E., Do, V.T., Ghamizi, M., Mock, K., Kebapci, U. et al. (2017b). Phylogeny of most species rich freshwater bivalve family (Bivalvia: Unionida: Unionidae): Defining modern subfamilies and tribes. Molecular Phylogenetics and Evolution, 106, 174-191. https://doi.org/10.1016/j.ympev.2016.08.021

Lopes-Lima, M., Hinzmann, M., Varandas, S., Froufe, E., Reis, J., Moreira, C. et al. (2020). Setting the stage for new ecological indicator species: A holistic case study on the Iberian dolphin freshwater mussel Unio delphinus Spengler, 1793. Ecological Indicators, 111, 105987. https:// doi.org/10.1016/j.ecolind.2019.105987

Lopes-Lima, M., Riccardi, N., Urbanska, M., Koehler, F., Vinarski, M., Bogan, A.E. et al. (2021). Major shortfalls impairing knowledge and conservation on freshwater molluscs. Hydrobiologia, 848(12-13), 2831-2867. https://doi.org/10.1007/s10750-021-04622-w
Lopes-Lima, M., Sousa, R., Geist, J., Aldridge, D.C., Araujo, R., Bergengren, J. et al. (2017c). Conservation status of freshwater mussels in Europe: State of the art and future challenges. Biological Reviews, 92(1), 572-607. https://doi.org/10.1111/brv.12244

Lopes-Lima, M., Teixeira, A., Froufe, E., Lopes, A., Varandas, S. \& Sousa, R. (2014). Biology and conservation of freshwater bivalves: Past, present and future perspectives. Hydrobiologia, 735, 1-13. https://doi.org/10. 1007/s10750-014-1902-9

López, M.A. \& Altaba, C.R. (2005). Fish host determination for Margaritifera auricularia (Bivalvia: Unionoida): Results and implications. Bollettino Malacologico, 41, 89-98.

López, M.A., Altaba, C.R., Rouault, T. \& Gisbert, E. (2007). The European sturgeon Acipenser sturio is a suitable host for the glochidia of the freshwater pearl mussel Margaritifera auricularia. Journal of Molluscan Studies, 73(2), 207-209. https://doi.org/10.1093/mollus/eym007

Mandahl-Barth, G. (1988). Studies on African freshwater bivalves. In: Charlottenlund. Denmark: Danish Bilharziasis Laboratory.

MARM. (2009). Estrategia Nacional Para la conservación de la almeja de río (Margaritifera auricularia) en España. Madrid: Ministerio de Medio Ambiente y Medio Rural y Marino.

Modesto, V., Ilarri, M., Souza, A.T., Lopes-Lima, M., Douda, K., Clavero, M. et al. (2018). Fish and mussels: Importance of fish for freshwater mussel conservation. Fish and Fisheries, 19(2), 244-259. https://doi. org/10.1111/faf.12252

Murzina, S.A., leshko, E.P. \& Zotin, A.A. (2017). The freshwater pearl mussel Margaritifera margaritifera L.: Metamorphosis, growth, and development dynamics of encysted glochidia. Biology Bulletin, 44(1), 6-13. https://doi.org/10.1134/S106235901701006X

Österling, M.E. \& Larsen, B.M. (2013). Impact of origin and condition of host fish (Salmo trutta) on parasitic larvae of Margaritifera margaritifera. Aquatic Conservation: Marine and Freshwater Ecosystems, 23(4), 564-570. https://doi.org/10.1002/aqc.2320

Prié, V., Philippe, L. \& Cochet, G. (2011). Plan National d'Actions en faveur de la Grande Mulette Margaritifera auricularia - 2012-2017. Ministère de l'écologie, du développement Durable, Des Transports et du Logement, Paris.

Reis, J., Collares-Pereira, M.J. \& Araujo, R. (2014). Host specificity and metamorphosis of the glochidium of the freshwater mussel Unio tumidiformis (Bivalvia: Unionidae). Folia Parasitologica, 61(1), 81-89. https://doi.org/10.14411/fp.2014.005

Soler, J., Boisneau, C., Jugé, P., Richard, N., Guerez, Y., Morisseau, L. et al. (2019). An unexpected host for the endangered giant freshwater pearl mussel Margaritifera auricularia (Spengler, 1793) as a conservation tool. Aquatic Conservation: Marine and Freshwater Ecosystems, 29(10), 1-13. https://doi.org/10.1002/aqc.3164

Soler, J., Wantzen, K.M., Jugé, P. \& Araujo, R. (2018). Brooding and glochidia release in Margaritifera auricularia (Spengler, 1793) (Unionoida: Margaritiferidae). Journal of Molluscan Studies, 84(2), 182-189. https://doi.org/10.1093/mollus/eyy008

Sousa, R., Teixeira, A., Benaissa, H., Varandas, S., Ghamizi, M. \& Lopezlima, M. (2019). Refuge in the sāqya: Irrigation canals as habitat for one of the world's 100 most threatened species. Biological Conservation, 238, 108209. https://doi.org/10.1016/j.biocon.2019. 108209

Sousa, R., Teixeira, A., Santos, A., Benaissa, H., Varandas, S., Ghamizi, M. et al. (2018). Oued Bouhlou: A new hope for the Moroccan pearl mussel. Aquatic Conservation: Marine and Freshwater Ecosystems, 28(1), 247-251. https://doi.org/10.1002/aqc.2825

Sousa, R., Varandas, S., Teixeira, A., Ghamizi, M., Froufe, E. \& LopesLima, M. (2016). Pearl mussels (Margaritifera marocana) in Morocco: Conservation status of the rarest bivalve in African fresh waters. Science of the Total Environment, 547, 405-412. https://doi.org/10. 1016/j.scitotenv.2016.01.003

Stoeckl, K., Denic, M. \& Geist, J. (2020). Conservation status of two endangered freshwater mussel species in Bavaria, Germany: Habitat 
quality, threats, and implications for conservation management. Aquatic Conservation: Marine and Freshwater Ecosystems, 30(4), 647-661. https://doi.org/10.1002/aqc.3310

Strayer, D.L., Downing, J.A., Haag, W.R., King, T.L., Layzer, J.B., Newton, T. J. et al. (2004). Changing perspectives on pearly mussels, North America's most imperiled animals. Bioscience, 54(5), 429-439. https:// doi.org/10.1641/0006-3568

Taeubert, J.E., Denic, M., Gum, B., Lange, M. \& Geist, J. (2010). Suitability of different salmonid strains as hosts for the endangered freshwater pearl mussel (Margaritifera margaritifera L.). Aquatic Conservation: Marine and Freshwater Ecosystems, 20(7), 728-734. https://doi.org/10. 1002/aqc.1147

Taeubert, J.E., Gum, B. \& Geist, J. (2012). Host-specificity of the endangered thick-shelled river mussel ((Unio crassus), Philipsson 1788) and implications for conservation. Aquatic Conservation: Marine and Freshwater Ecosystems, 22(1), 36-46. https://doi.org/10.1002/aqc. 1245

Van Damme, D. \& Ghamizi, M. (2010). Margaritifera marocana. The IUCN Red List of Threatened Species 2010: E.T184701A8317425. https:// doi.org/10.2305/IUCN.UK.2010-3.RLTS.T184701A8317425.en.

[Accessed 06 April 2019]
Young, M.R. \& Williams, J. (1984). The reproductive biology of the freshwater pearl mussel Margaritifera margaritifera (Linn.) in Scotland. I. Field Studies. Archiv für Hydrobiologie, 99, 405-422.

Zieritz, A., Bogan, A.E., Froufe, E., Klishko, O., Kondo, T. \& Kovitvadhi, U. (2018). Diversity, biogeography and conservation of freshwater mussels (Bivalvia: Unionida) in East and Southeast Asia. Hydrobiologia, 810(1), 29-44. https://doi.org/10.1007/s10750-017-3104-8

How to cite this article: Benaissa, H., Ghamizi, M., Teixeira, A., Sousa, R., Rassam, H., Varandas, S. et al. (2021). Preliminary data on fish hosts and their conservation importance for the critically endangered Pseudunio marocanus (Pallary, 1918). Aquatic Conservation: Marine and Freshwater Ecosystems, 1-10. https://doi.org/10.1002/aqc.3756 